\title{
A ÁGUA DE LASTRO E A NECESSIDADE DE EFETIVIDADE DAS NORMAS DE PROTEÇÃO DA BIODIVERSIDADE MARINHA NO CONTEXTO AMAZÔNICO
}

\author{
Renã Margalho Silva ${ }^{1}$ \\ Centro de Instrução Almirante Braz de Aguiar/Marinha do Brasil
}

Eliane Cristina Pinto Moreira
Universidade Federal do Pará (UFPA)

\section{RESUMO}

Precedentes demonstram que a água de lastro pode influenciar no equilíbrio biológico de espécies nativas, proliferar doenças e gerar impactos econômicos, sanitários e sociais. Em face das projeções de crescimento da movimentação portuária na Região Amazônica, agrava-se o risco de danos ambientais, com possível afetação de populações tradicionais locais, que estão à mercê da ineficiência do controle da água de lastro nos portos brasileiros. O presente artigo, por meio do método dedutivo, visa analisar as normas que regulam o gerenciamento da água de lastro, sinalizando alguns pontos falhos da legislação nacional, e o agravamento dos riscos à biodiversidade e populações locais. Isso foi feito com base em precedentes de acidentes e projeções de crescimento da movimentação de carga no Porto de Vila do Conde, o que está diretamente relacionado ao aumento do tráfego de navios e agravamento de riscos de poluição ambiental. Conclui-se, portanto, que a ineficiência da regulação e a ineficácia da fiscalização da água de lastro de navios agravam a vulnerabilidade da Região Amazônica e de seus habitantes.

Palavras-chave: água de lastro; bioinvasão; populações locais; Porto de Vila do Conde; Região Amazônica.

1 Mestrando em Direito pela UFPA). Especialista em Direito Marítimo e Portuário pela Universidade Católica de Santos (UNISANTOS). Coordenador acadêmico e professor da Pós-Graduação lato sensu de Logística Portuária e Direito Marítimo do Instituto Navigare. Professor assistente do Centro de Instrução Almirante Braz de Aguiar/Marinha do Brasil. E-mail: rmargalho.jus@gmail.com

2 Doutora em Desenvolvimento Sustentável do Trópico Úmido pela UFPA. Pós-Doutora pela Universidade Federal de Santa Catarina (UFSC). Mestre em Direito pela Pontifícia Universidade Católica de São Paulo (PUC-SP). Graduada em Direito pela UFPA. Promotora de justiça do Ministério Público do Estado do Pará e Professora da UFPA. E-mail: moreiraeliane@hotmail.com 


\section{THE BALLAST WATER AND THE NECESSITY OF EFFECTIVENESS OF PROTECTION RULES FOR THE MARINE BIODIVERSITY IN THE AMAZONIAN CONTEXT}

\section{ABSTRACT}

Precedents demonstrate that ballast water can influence in the biological balance of native species, proliferate diseases and generate economic, sanitary and social impacts. In view of the projections for growth of port traffic in the Amazon region, the risk of environmental damage is aggravated, with the possible affectation of local traditional populations, who are at the mercy of the inefficiency in the control of ballast water in Brazilian ports. This article, by means of the deductive method, aims to analyze the rules that control ballast water management, indicating some flaws in the internal regulations, and the worsening of risk to biodiversity and local populations. All this based on accidents precedents and on the projection of growth in cargo handling at Port of Vila do Conde, what is directly related to the growth of vessels traffic and worsening of risk to environmental pollution. Therefore concludes that the inefficiency of regulation and the inefficacy of the control of the ballast water of ships aggravate the vulnerability of the Amazon Region and its inhabitants.

Keywords: Amazon region; ballast water; bioinvasion; local populations; Port of Vila do Conde. 


\section{INTRODUÇÃO}

Com o fenômeno da globalização, cada vez mais se nota a formação de complexas cadeias econômicas, nas quais países formam acordos comerciais, blocos econômicos, entre outros instrumentos que interligam, direta ou indiretamente, a economia mundial.

A relação de comércio exterior é uma realidade mundial para todas as soberanias, em diferentes intensidades. Um dos meios de consolidação dessa interligação econômica é a realização do comércio internacional de mercadorias por meio de importação e exportação.

É pelo modal marítimo, representado por diversos tipos de embarcações, que ocorre a maior parte da movimentação de carga no mundo. Os navios cargueiros são responsáveis por $90 \%$ da movimentação internacional dessa carga. No Brasil, o modal marítimo é responsável por $95 \%$ da movimentação de carga (MARTINS, 2013). É em função disso que milhares de espécies exóticas são transportadas em seus tanques e, após serem transferidas de um local para outro, são inseridas em habitats que lhes são estranhos, causando impacto ao meio ambiente, à economia dos países e à saúde humana e animal.

A regulamentação do gerenciamento da água de lastro, no Brasil, de normas internacionais, constitucionais e infraconstitucionais, impõe uma série de medidas que devem ser observadas, no momento da realização do lastro e deslastro, pela tripulação do navio, pelos entes federados e por empresas que utilizam diretamente a exploração portuária, visando que os riscos de poluição sejam mitigados e possibilitem ao Poder Público exercer um controle eficiente.

A evolução normativa constitui um avanço para a prevenção dos impactos ambientais causados pelas embarcações, porém, o controle é falho e tem se mostrado ineficiente, no que tange à proposta da Convenção Internacional para o Controle e Gerenciamento da Água de Lastro e Sedimentos dos Navios (BWM).

A Região Amazônica é palco de vasta diversidade biológica e cultural, com proteção jurídica especial, em âmbito nacional e internacional. O risco inerente da água de lastro, neste contexto espacial, por diversos fatores, agrava-se, dada a vulnerabilidade do meio ambiente e das comunidades tradicionais locais que habitam a margem dos rios. O cenário tende a piorar diante da projeção de crescimento de movimentação portuária no chamado arco norte ${ }^{3}$.

3 "O projeto Arco Norte é o sistema de transportes, em seus vários modos, responsável pelo escoamento de cargas e insumos com a utilização dos portos ao norte do Brasil, desde Porto Velho, 
O presente artigo tem como objetivo a análise do perigo da água de lastro na Região Amazônica, avaliando se a legislação (nacional e internacional) consegue assegurar o equilíbrio e a diversidade ecológica da Amazônia, bem como o respeito ao Princípio da Prevenção. Para tanto, serão utilizados exemplos de casos de poluição por água de lastro ocorridos no Brasil, inclusive na região que é objeto da presente análise, comparando-os com a projeção de crescimento de movimentação de navios no Porto de Vila do Conde, divulgados por órgãos oficiais.

Nesse sentido, utilizaremos o método dedutivo, com técnicas de levantamento documental e bibliográfico.

\section{A ÁGUA dE LASTRO E A SUA REGULAÇÃO}

O lastro é o peso colocado a bordo de uma embarcação para gerar equilíbrio e estabilidade. Não é considerado carga, tampouco possui outra função comercial. Sua operacionalização está relacionada à segurança da navegação.

Para uma operação segura, é necessário que a embarcação opere entre um intervalo de peso (peso de segurança mínimo e peso de segurança máximo), o que repercute diretamente em seu calado, centro de gravidade e, por conseguinte, em sua estabilidade. Quando a embarcação está leve e o limite de peso mínimo não é atingido, necessita-se incorporar, temporariamente, peso externo.

Em razão do desenvolvimento de bombas, o lastro utilizado hoje é predominantemente água, por seu fácil manuseio. A água colocada a bordo de uma embarcação é chamada de água de lastro, sendo armazenada em compartimentos específicos e especializados, chamados tanques de lastro, tendo a finalidade de controlar a estabilidade ${ }^{4}$, forças estruturais, trim $^{5}$, banda $^{6}$ e o calado ${ }^{7}$ da embarcação.

O navio é projetado para captar água, e armazená-la nos tanques de lastro, visando complementar o peso até que atinja o limite mínimo de calado para uma navegação segura. O lastro é de fundamental importância

em Rondônia, passando pelo Estados do Amazonas, Amapá e Pará, até o sistema portuário de São Luís, no Maranhão" (BRASIL, 2016, p. 11).

4 Capacidade da embarcação de retornar a posição de equilíbrio, depois da ação de uma força externa.

5 Diferença entre o calado de proa com o calado de popa.

6 Diferença entre o calado de bombordo e o calado de boreste.

7 Corresponde à distância da lâmina d'água, até a quilha da embarcação. Em síntese, é a profundidade que a embarcação se encontra em determinado momento. 
para a manutenção da segurança da navegação, principalmente quando o navio está "leve", ou seja, descarregado, ou com pouca carga.

O navio, ao realizar um descarregamento de mercadoria, para manter a estabilidade (operar entre os intervalos de pesos de segurança), enche de água os seus tanques de lastro na área em que se encontra. Ao se deslocar para carregamento em outro porto, o navio está cheio de água de lastro e sem carga. Chegando ao local de embarque da carga, a água de lastro da localidade de origem é despejada, para que os produtos sejam embarcados e o navio continue operando entre o intervalo de segurança de peso.

Com a intensificação do comércio mundial e a modernização dos navios mercantes, juntamente com as mercadorias transportadas pelas embarcações, a água de um determinado ecossistema migra, nos tanques de lastro, para um nicho estranho, levando consigo espécies exóticas, gerando o fenômeno da bioinvasão ${ }^{8}$, especialmente grave na região Amazônica.

\subsection{Marco normativo}

O dano ambiental derivado de água de lastro é, em regra, de verificação mediata e difícil reversão, podendo influenciar diversos países.

Haja vista a grande relevância internacional do tema, diversas normas, de âmbito interno e internacional, vêm regulamentando o tema, visando prevenir danos ambientais e controlar o gerenciamento da água de lastro nos navios.

A Organização Marítima Internacional (IMO) ${ }^{9}$, em fevereiro de 2004, por meio do Comitê de Proteção ao Meio Marinho (MPEC), propôs a Convenção Internacional para o Controle e Gerenciamento da Água de Lastro e Sedimentos dos Navios ${ }^{10}$, objetivando prevenir e eliminar os riscos de poluição por água de lastro, derivados da introdução de organismos aquáticos nocivos e agentes patogênicos, em nichos ecológicos diferentes.

A água de lastro é definida juridicamente pela BWM como "água com suas partículas suspensas levada a bordo de um navio para o controle do

8 "Bioinvasão ou invasão biológica é o ato ou efeito de um ou mais organismos invadirem e se estabelecerem em ambientes onde não haviam registros anteriores para a espécie. Entretanto, existem dois tipos de invasões: expansões e introduções. As expansões consistem na dispersão de organismos por mecanismo natural e as introduções ocorrem quando as espécies são transportadas por atividades humanas, intencionalmente ou não, para uma área onde não ocorriam" (LUZ DE SOUZA, 2010, p. $01)$.

9 Entidade especializada em assuntos marítimos de interesse internacional, vinculada à Organização das Nações Unidas (ONU). É competente por elaborar, organizar e reunir Convenções de Direito Marítimo Internacional Público.

10 International Convention for the Control and Management of Ships'Ballast Water and Sediments 
trim, banda, calado, estabilidade ou tensões do navio". Esta Convenção reconhece a transferência e introdução de Organismos Aquáticos Nocivos e Agentes Patogênicos através da Água de Lastro dos navios como uma ameaça à conservação e uso sustentável da diversidade biológica.

No mesmo sentido, a Convenção da Diversidade Biológica também assegura a proteção e conservação da biodiversidade marinha, postula especificamente a necessidade de adoção de mecanismos destinados à avaliação de impactos e minimização de impactos negativos sobre a biodiversidade, prevendo o dever dos Estados de adotarem medidas que propiciem a informação de países impactados por danos ou riscos oriundos de atividades exercidas sobre sua jurisdição, que possam se fazer sentir no território de outros Estados. Tal como ocorre com a água de lastro, desta forma, é imposto aos Estados o dever de:

d) Notificar imediatamente. no caso em que se originem sob sua jurisdição ou controle, perigo ou dano iminente ou grave à diversidade biológica em área sob jurisdição de outros Estados ou em áreas além dos limites da jurisdição nacional, os Estados que possam ser afetados por esse perigo ou dano, assim como tomar medidas para prevenir ou minimizar esse perigo ou dano (ONU, 1992, p. 14).

Em âmbito nacional, destacamos a Constituição Federal, que atribui ao meio ambiente equilibrado o status de bem essencial para a sadia qualidade de vida do povo, protegendo especificamente o patrimônio genético da biodiversidade em face de atividades que representem riscos à sua integridade.

Infraconstitucionalmente, destacamos, a Lei n. 9.537/97, que trata da segurança do tráfego aquaviário, a Lei n. 9.605/1998 e o Decreto n. 6.514/08, sobre crimes ambientais e infrações administrativas. Tratando-se de normas infralegais, tem-se a Norma da Autoridade Marítima (NORMAM) 20, que regulamenta o gerenciamento de água de lastro em navios e a Resolução da Diretoria Colegiada (RDC) 72/2008, da Agência Nacional de Vigilância Sanitária (ANVISA), para controle da água de lastro das embarcações.

A BWM, que entrou em vigor em setembro de 2017, determina que os países signatários se comprometam a fiscalizar os navios localizados em suas zonas marítimas, ou sob sua autoridade, dando condições para as embarcações deslastrarem em instalações de captação especializadas, possibilitando a limpeza e o reparo dos tanques de lastro em seu território. Além das obrigações dos países signatários, a Convenção estabelece procedimentos mínimos que os navios devem seguir para minimizar os 


\section{riscos de poluição por água de lastro e uma série de documentos que presumirão adequação da embarcação à $\mathrm{BWM}^{11}$.}

Os navios que estiverem submetidos à Convenção deverão possuir um Certificado Internacional de Gerenciamento de Água De Lastro ${ }^{12}$, um livro de registro de operações com água de lastro $^{13}$ e um plano de gerenciamento de água de lastro individualizado ${ }^{14}$. A Convenção também prevê os procedimentos de trocas oceânicas de água de lastro $^{15}$ e outras formas de tratamento aprovada pela $\mathrm{IMO}^{16}$.

11 O Brasil internalizou a Convenção Internacional sobre Gerenciamento de Água de Lastro e Sedimentos de Navio por meio do Decreto Legislativo 148/2010, de 15 de março de 2010. Em 14 de abril de 2010, foi depositado o instrumento de ratificação junto à IMO. A BWM é aplicável somente a navios que estejam autorizados a arvorar a bandeira de um Estado signatário, ou que operem sob autoridade deste, realizando viagens internacionais, ou que operem exclusivamente em um Estado diferente de sua bandeira, salvo autorização expressa do mesmo. A Convenção não se aplica aos navios imunes ou àqueles que sejam projetados para operar sem lastro, ou com lastro fixo.

12 O Certificado Internacional de Gerenciamento de Água de Lastro é conferido pelo país de bandeira da embarcação, ou que exerce soberania imediata sobre a mesma, com validade de até cinco anos. Tem validade internacional, dando, ao navio, garantia de presunção de adequação a Convenção. O Certificado não impede o país costeiro de realizar inspeções e conferir a autenticidade do documento. Sua emissão está condicionada a uma vistoria do país competente, ou agentes que o representem, onde analisarão o Plano de Gerenciamento de Água De Lastro do navio (PGAL) e sua manutenção estão condicionados a uma série de vistorias periódicas.

13 O livro de registro da água de lastro é documento oficial da embarcação. Todo o navio que esteja submetido a BWM é obrigado a ter a bordo tal documento, que deverá constar de informações da operação de lastro. Seu modelo está descrito no apêndice 2 da Convenção. As regras de preenchimento são similares às do Diário de Navegação, devendo o oficial responsável, assinar ao final do registro e o comandante, como responsável pela embarcação e tripulação, deve convalidar todos os registros feitos por seus subordinados, assinando ao final da página. É proibida a rasura, devendo utilizar-se a expressão "digo", entre vírgulas, para eventuais correções. Caso o registro já tenha sido encerrado, sua retificação deverá ser feita por meio da expressão "Em tempo", seguida do texto correto. O registro deve conter, em regra, a data, horário e local da captação e da descarga do lastro, estimativa do volume captado e/ou deslastrado, se alguma anormalidade que impediu o deslastro conforme procedimento da BWM ocorreu, informar se o plano de gerenciamento de água de lastro foi cumprido e, ao final, a assinatura do oficial que realizou o registro. O livro deverá ser mantido a bordo, após o último registro, por um período de dois anos e, após o transcurso do prazo, deverá ficar em posse da empresa de navegação responsável pelo navio por mais três anos.

14 O Plano de Gerenciamento de Água de Lastro é o conjunto de medidas operacionais e preventivas, incluindo o plano de emergência nos casos de vazamento, que cada navio deve possuir de forma individualizada, devendo conter obrigatoriamente: 1- procedimentos de segurança detalhados para o navio e tripulação associados ao gerenciamento da água de lastro; 2- descrição detalhada para implementação do PGAL; 3- procedimentos para destinação dos sedimentos no mar e em terra; 4procedimentos para descarga da água de lastro; 5- designação de oficial responsável pelo cumprimento do PGAL; 6- prescrições dos relatórios previstos na BWM; 7- tradução do Plano em um dos idiomas oficiais da IMO (inglês, Frances, ou espanhol).

15 A Convenção também prevê procedimentos para a operação de descarga e captação de água de lastro. A troca da água de lastro deve se dar, em regra, em águas oceânicas. Ao se aproximar do território marítimo de um país, a embarcação, além de duzentas milhas náuticas da costa, em zonas com profundidade de, no mínimo, 200 metros, tem que realizar a troca da água de lastro. Nos casos em que a distância mínima do deslastro não for respeitada, os motivos que justificaram a relativização da norma tem que ser explanados no livro de registro de água de lastro, devendo a embarcação deslastrar o mais distante possível da costa, a uma profundidade de pelo menos 200 metros, não podendo ultrapassar a distância mínima de 50 milhas da costa.

16 Atualmente, a maioria das embarcações utilizam a troca da água de lastro como forma de tratamento. 
Os Princípios da Segurança da Navegação, da Salvaguarda da Vida Humana e da Proteção ao Meio Ambiente Marinho, são elencados na BWM, e prevalecem sobre os procedimentos de lastro e deslastro. ${ }^{17}$

\subsection{Regulamentação sobre água de lastro no Brasil}

As normas internas não devem ser divergentes da Convenção, sob pena de gerar grave insegurança jurídica e repercutir negativamente nos Princípios da Segurança da Navegação, da Padronização e Liberdade de Navegação. Consequentemente, todos os países com grande tradição marítima elaboram normas em consonância com os preceitos da Norma Internacional, podendo complementá-la com novas exigências que tornem as medidas mais eficientes no contexto local, para a consecução da sua finalidade.

No Brasil, em âmbito constitucional, podemos destacar os artigos 170, que define a proteção do Meio ambiente como um dos princípios da ordem econômica, e o artigo 225, que estabelece que o "meio ambiente ecologicamente equilibrado, bem de uso comum do povo e essencial à sadia qualidade de vida" é direito de todos.

Há ainda a Lei n. 9.605/1998 e o respectivo Decreto Regulamentador n. 6.514/08 (Lei de Crimes Ambientais e Infrações Administrativas), que preveem responsabilidades penais, civis e administrativas derivadas de condutas e atividades lesivas ao meio ambiente, incluindo poluição causada por água de lastro.

Os destaques são as punições de cunho penal, com ação de natureza pública incondicionada, podendo variar a pena de seis meses a oito anos, dependendo da conduta e das circunstâncias agravantes. Na esfera administrativa também há a previsão de multas em decorrência de infrações ambientais.

A suprarreferida Lei prevê o Princípio da Cooperação Internacional para a Preservação do Meio Ambiente, determinando que o Brasil preste,

Somente no final de 2017, foram lançados ao mar os primeiros navios de bandeira brasileira, da nova frota da Transpetro, com duplo sistema de tratamento, que dispensa a troca por águas oceânicas.

$17 \mathrm{O}$ comandante da embarcação pode deslastrar em desconformidade com as exigências descritas na Convenção se, justificadamente e de forma razoável, decidir que a troca de lastro ameaçaria a estabilidade do navio, e/ou a segurança dos tripulantes e passageiros. O fundamento de tal permissividade é a valoração da vida, ponderação de riscos e razoabilidade. A BWM tem como fim a preservação do meio ambiente. Um naufrágio tem um potencial maior de poluição do que água de lastro, portanto, não seria razoável exigir uma conduta do comandante que representasse um risco maior de poluição. Ademais, a vida das pessoas a bordo é princípio expresso e soberano na maioria das Convenções de Direito Marítimo Público, relativizando procedimentos prefixados. 
no que concerne ao meio ambiente, a necessária cooperação a outros países, sem qualquer ônus, resguardadas a soberania nacional, a ordem pública e os bons costumes, considerando a Marinha do Brasil como Autoridade Ambiental, no que concerne à poluição derivada de navios.

A Resolução da Diretoria Colegiada da ANVISA 72/2008 trata da "promoção da saúde nos portos de controle sanitário instalados em território nacional, e embarcações que por eles transitem". A RDC 72/08 garante a prerrogativa da Agência Nacional de Vigilância Sanitária de realizar visitas nas embarcações localizadas em território brasileiro, para coletar água dos tanques de lastro e submetê-la a testes. Impõe à tripulação da embarcação, ao solicitar a livre prática, o dever de informar sobre a água de lastro que está a bordo e entregar um formulário, nos moldes do modelo anexado na própria norma da ANVISA.

A Lei n. 9.537/97, conhecida como Lei de Segurança do Tráfego Aquaviário (LESTA), em seu artigo $4^{\circ}$, inciso VII, determina que é atribuição da Autoridade Marítima "estabelecer os requisitos referentes às condições de segurança e habitabilidade e para a prevenção da poluição por parte de embarcações, plataformas ou suas instalações de apoio".

O Comando da Marinha (Autoridade Marítima), por meio da Diretoria do Portos e Costas, criou duas Normas da Autoridade Marítima (NORMAM), com força de Resolução, que regulamentam o processo de controle da água de lastro em embarcações.

A NORMAM 08, trata das normas para o tráfego e permanência de embarcações em águas jurisdicionais brasileiras, estabelece que as embarcações que forem adentrar em águas brasileiras, oriundas de outros países, precisam enviar à Autoridade Marítima um formulário contendo informações sobre o lastro do navio. A NORMAM 20 regulamenta o gerenciamento de água de lastro em navios. É a norma brasileira mais específica sobre o assunto.

Dentre os destaques da norma, apontamos as diretrizes mais específicas para o procedimento de troca de água de lastro. A NORMAM determina que o navio, conforme preceituado pela BWM, troque a água de lastro em águas oceânicas, em um volume estimado de três vezes a capacidade de seus tanques de lastro, exceto nos casos de comprometimento da segurança da navegação, nos quais a embarcação deverá trocar a água de lastro, assim que possível, sem comprometer a navegabilidade, no local mais profundo e distante da costa.

A aplicação da NORMAM 20 é mais ampla, abrangendo todas as 
embarcações dotadas de tanques de água de lastro, que utilizem os portos e terminais brasileiros. Por ser uma norma interna, abrange mais situações, inclusive das embarcações que só trafeguem em água jurisdicionais brasileiras.

No que tange ao procedimento de troca de água de lastro, a NORMAM adota os mesmos procedimentos da Convenção (além de 200 milhas, com profundidade mínima de 200 metros, ou, para preservar a segurança da embarcação, antes das 200 milhas, o mais distante possível da terra mais próxima, a pelo menos 50 milhas da costa, com profundidade mínima de 200 metros), permitindo, ainda, a troca antes de 50 milhas da costa, no trecho de maior profundidade, não estabelecendo limites de distância ou fundura, quando a derrota da embarcação não ultrapassar esta distância. Em casos de risco à segurança da navegação, o comandante pode decidir, mediante a justificativa escrita, não realizar a troca da água de lastro, em conformidade com os Princípios da Segurança da Navegação e da Salvaguarda da Vida Humana.

É proibido o deslastro em áreas ecologicamente sensíveis ${ }^{18}$. Como forma de controle, a NORMAM 20 estabelece que, além dos itens dispostos na Convenção (Livro de Registro de Água de Lastro, o Plano de Gerenciamento da Água de Lastro do navio e o Certificado Internacional), o Brasil poderá verificar se o formulário de água de lastro foi corretamente preenchido, coletar água, verificando as condições físico-químicas ${ }^{19}$, para averiguar a veracidade das informações que constam nos documentos, cruzar informações descritas no Livro de Água de Lastro, com outros livros oficiais a bordo ${ }^{20}$.

Referida normativa também estabelece a competência do agente da Autoridade Marítima para lavrar o auto de infração ambiental e instaurar o processo administrativo. Para além dos aspectos já mencionados, estabelece ainda que infrações derivadas de inobservância aos preceitos nela contidos seguirão os procedimentos e as punições previstas na Lei n. 9.605/98 e o Decreto n. 6.514/08, impondo ao autor da infração, multa que varia entre $R \$ 5.000,00$ e $R \$ 50.000 .000,00$, ou $R \$ 150.000 .000,00$ em caso de reincidência.

18 As áreas ecologicamente sensíveis são destacadas na carta náutica.

19 O agente da Autoridade Marítima poderá realizar exames na água de lastro, por meio do refratômetro, para verificar a salinidade da água. Conforme o resultado, pode-se apurar se a água contida nos tanques de lastro são da mesma região em que, de acordo com o Livro de Registro de Água de Lastro e o formulário de água de lastro, foi realizada a troca da água.

20 A bordo de um navio, vários livros com valor documental se fazem presentes. Destacamos o Diário de Navegação, Diário de Máquinas, Livro de Óleo, dentre outros. 
A versão anterior da NORMAM 20, com as suas respectivas emendas ${ }^{21}$, estabelecia procedimentos específicos para a navegação fluvial. Levava em consideração a variedade de ecossistemas nas diversas bacias fluviais. Antes, um navio originário de uma bacia fluvial, só poderia deslastrar em outra se realizasse a troca de lastro por duas vezes em uma zona de transição.

A revisão da Norma da Autoridade Marítima que regulamenta a operação com água de lastro é falha ao considerar um número restrito de ecossistemas aquáticos, que não condiz com a realidade, sobretudo amazônica. A simples alteração do ecossistema de uma espécie transportada por água de lastro pode gerar desequilíbrio.

Portanto, a Autoridade Marítima tem que considerar a complexidade e variedade dos diversos ecossistemas aquáticos nacionais. Destacamos o estudo sobre ecossistemas brasileiros, realizado pela Secretaria de Biodiversidade e Florestas, ligada ao Ministério do Meio Ambiente:

A extensão e a diversidade da Zona Costeira e da Zona Marinha brasileiras, em termos de ecossistemas e espécies, configuram uma situação distintiva, em que a biodiversidade local e as inúmeras espécies endêmicas se sobrepõem rotas migratórias e sítios de condicionamento e desova para espécies migratórias de distribuição global. Assim, a preservação ou a degradação de determinados ecossistemas deixa de ter um efeito puramente local. A perda de espécies endêmicas implica o empobrecimento da biodiversidade global, e a devastação ou a fragmentação de habitats pode gerar efeitos amplificados sobre diversas populações e suas rotas migratórias, interferindo na dinâmica de ecossistemas muitas vezes distantes das áreas afetadas (BRASIL, 2002b, p. 272).

A atual NORMAM 20 é omissa em um ponto de grande importância para o cumprimento da finalidade da Convenção (eliminar a poluição por água de lastro). Em seu capítulo 3, item 3.2, determina que "[...] as embarcações que trafeguem entre portos/terminais fluviais de bacias hidrográficas distintas, quando o trânsito se der por mar, deverão realizar a troca da Água de Lastro", caso não possuam o sistema de tratamento de água de lastro, nada mais prevendo para embarcações que naveguem exclusivamente por vias fluviais. As embarcações que trafeguem entre duas bacias hidrográficas não necessitarão trocar o lastro.

O Brasil é um país de dimensões continentais. Em uma mesma bacia hidrográfica, podemos encontrar vários ecossistemas distintos ${ }^{22}$. Na Bacia

21 A NORMAM 20 foi criada pela Portaria 52/DPC/2005. A presente norma foi emendada por meio das Portarias 80/DPC/2005, 95/DPC/2005, 01/DPC/2006, 66/DPC/2006 e 125/DPC/2008.

22 "A descarga amazônica equivale a quase cinco vezes a descarga do rio Zaire, o segundo em descarga do mundo, e a $20 \%$ de toda a água doce que é despejada nos oceanos dos planetas por todos os rios" 
Amazônica, o meio ambiente é heterogêneo, possuindo vasta diversidade de paisagens, espécies e povoações humanas que nele estão inseridos (BRASIL, 2002b). Verificamos três tipos de rios, com peculiaridades ambientais distintas (rios de águas brancas, rios de águas pretas e rios de águas claras) ${ }^{23}$. Considerar desnecessária a renovação do lastro na navegação interior ${ }^{24}$ é sinônimo de assumir um risco de poluição ambiental por água de lastro, convalidada pelos procedimentos descritos na Norma da Autoridade Marítima 20.

Para mitigar os riscos de poluição por água de lastro, é necessário que a NORMAM 20 determine um mapa de ecossistemas marinhos do Brasil, sobretudo na navegação interior, onde a renovação de lastro é dispensada, estabelecendo zonas de transições onde o navio que esteja realizando uma rota de navegação interior possa, dessa maneira, trocar seu lastro com menor potencial ofensivo ao meio ambiente.

Outro ponto a ser destacado dá-se na navegação de cabotagem ${ }^{25}$. A NORMAM prevê que as embarcações não precisam desviar sua rota para o cumprimento do procedimento da troca de lastro. Caso a embarcação realize uma viagem de cabotagem, estabelecendo uma rota a uma distância inferior a cinquenta milhas náuticas da costa, deverá realizar a troca de lastro no trecho de maior profundidade, sem um limite mínimo de distância.

Tal permissividade representa um grande risco para o meio ambiente. A medida mais adequada ao artigo 225 da Constituição Federal do Brasil e a BWM seria a exigência de navios com sistema de tratamento próprio, que dispensassem a necessidade de troca da água de lastro (economicamente inviável), ou a criação de um mapa de ecossistemas e zonas de transição, e/ou, quando o tráfego marítimo se der fora das águas interiores, a obrigatoriedade de estabelecer uma rota além das 50 milhas náuticas, para que a embarcação pudesse trocar o lastro sem alterar a rota.

Para potencializar a eficiência econômica e ambiental do transporte marítimo, as duas medidas deveriam ser adotadas em conjunto. Um navio só necessitaria traçar sua rota além das 50 milhas náuticas, caso passasse para outro ecossistema marinho, que não tivesse uma zona de transição e não possuísse sistema interno de tratamento de água de lastro.

(BRASIL, 2002b, p. 29)

23 Os rios de água branca (Solimões e Purus) carregam sedimentos de alta fertilidade. Os rios de água preta (Negro e Urubu) possuem alta acidez e contém poucos minerais. Finalmente, os rios de água claras (Tapajós e Xingú) possuem águas de qualidade média em termos de nutrientes (JUNK, 1979).

24 Navegação realizada atrás da linha base da costa.

25 Navegação entre portos nacionais 


\subsection{Dificuldades de controlar a poluição por água de lastro no Brasil}

A normatização sobre água de lastro, no Brasil, é relativamente desenvolvida, prevendo procedimentos eficientes de prevenção de impactos ambientais, adotando as diretrizes previstas na BWM, com algumas ressalvas que podem ser corrigidas pela autoridade marítima brasileira. Ademais, a efetividade dessas normas que é bastante questionável.

As normas que impõem à tripulação obrigações de envio documentos para as Autoridades Marítima e Sanitária do Brasil, como a RDC 72/09 e a NORMAM 08, com a respectiva informação da água armazenada nos tanques de lastro do navio, são formalmente eficientes. Só é autorizada a atracação, após o envio destes formulários.

Já as exigências que são de responsabilidade do Poder Público: fiscalizar a bordo das embarcações, como os documentos, certificados e, principalmente, a autenticidade das informações prestadas, são parcialmente eficientes. Levantamentos científicos já demonstraram que é comum que os navios deslastrem em desacordo com as normas brasileiras. A verificação se deu por meio do cruzamento dos dados contidos nos formulários oficiais e no livro de registro de água de lastro, com exames de salinidade realizados na água dos tanques de lastro de navios. Tais dados evidenciam uma falha na eficácia da norma.

Estudos realizados por pesquisadores do Centro de Instrução Almirante Braz de Aguiar (CIABA), em parceria com a Universidade Federal do Pará (UFPA), apontaram, com a análise da salinidade da água contida nos tanques de lastro de três navios que operam no Porto de Miramar, em Belém do Pará, que dois deles não realizaram a troca de lastro em águas oceânicas. Os registros contidos no livro de água de lastro e nos formulários, informavam que a operação de renovação do lastro tinha ocorrido em conformidade com as normas internas. Ficou evidenciado que os registros de uma embarcação não eram condizentes com as amostras de água de lastro coletadas (SIQUEIRA et al., 2012).

A ANVISA, em 2002, realizou 99 coletas de água de lastro, em 09 portos brasileiros. Verificou-se pela salinidade da água, que $62 \%$ das embarcações que afirmaram ter realizado a troca de lastro, conforme orientação da IMO à época, não a fizeram (BRASIL, 2002a).

Acredita-se que este cenário vem mudando lentamente. Pesquisa publicada em 2009, por Eliane Boldrini e Letícia Procopiak, realizada no Terminal Portuário da Ponta do Felix, no Paraná, constatou que a maioria dos navios testados realizaram a troca oceânica de água de lastro, mas 
ainda existem relatos que noticiam a possível alteração de informações dos documentos de controle, com finalidade de burlar a fiscalização.

Outro problema verificado foi a dificuldade de acesso a alguns dos tanques de lastro de várias embarcações, inviabilizando o exame em todos os tanques. A arquitetura de vários navios, principalmente os mais antigos, não leva em consideração facilitação da coleta de água de lastro (BOLDRINI; PROCOPIAK, 2005).

Letícia Procopiak (2009), em sua tese de doutorado, pesquisou sobre o conhecimento dos comandantes de navios sobre a bioinvasão por água de lastro nos portos do Paraná, e constatou que os oficiais brasileiros sabem que existe um risco de bioinvasão, mas não sabem o motivo, a importância e o impacto concreto que tal fenômeno pode acarretar ao meio ambiente e à saúde humana. $\mathrm{O}$ conhecimento dos oficiais da marinha mercante está voltado às questões pragmáticas de procedimentos, e em geral limita-se ao que está descrito em normas.

A pesquisadora concluiu que é importante uma campanha de conscientização ambiental que pudesse sensibilizar a tripulação dos navios, portuários e armadores, sobre os perigos da água de lastro. Os oficiais entrevistados deram, como sugestão unânime, a criação de um documentário de conscientização, que pudessem assistir a bordo do navio, no momento do tráfego, posto que quando a embarcação está atracada, torna-se difícil dar a devida atenção a campanhas educativas, em virtude do tempo escasso (PROCOPIAK, 2009).

Outro ponto importante é a conscientização ambiental desde a formação de oficiais da marinha mercante. Só existem duas instituições, no Brasil, que ministram o Curso de Bacharel em Ciências Náuticas, que habilitam para exercer o oficialato a bordo de embarcações, com habilitação em máquinas, ou náutica: o Centro de Instrução Almirante Braz de Aguiar, localizado em Belém; e o Centro de Instrução Almirante Graça Aranha, localizado no Rio de Janeiro.

Até o ano de 2012, a BWM não fazia parte da grade curricular dos cursos. Em 2013, a DPC atualizou o sumário das disciplinas, acrescentando a BWM e a NORMAM 20 como matéria complementar, inseridas na disciplina Legislação Marítima e Ambiental, em razão de sua relevância. A partir do final de 2015, quando a primeira turma concluinte com o novo sumário se forma, os novos oficiais mercantes terão uma base mais consolidada sobre os perigos da água de lastro para o meio ambiente marinho. 
Programas de pesquisa em monitoramento de água de lastro estão em fase de criação por diversas universidades brasileiras, com destaque para a Universidade de São Paulo (USP), que vem desenvolvendo aparelho de controle de lastro. Por meio deste equipamento, a Autoridade Marítima teria as informações sobre o local de lastro e propriedades físico-químicas da água, como $\mathrm{pH}$, oxigenação, turbidez, salinidade, temperatura e oxigênio dissolvido. O sistema proposto envia automaticamente as informações para as autoridades competentes, independente da tripulação. Testes em laboratórios foram bem-sucedidos, estando em andamento os testes em navios. (USP, 2013)

Outro destaque importante no desenvolvimento de sistemas eficazes de gerenciamento de água de lastro, em âmbito internacional, é o Global Ballast Water Management Program (GloBallast). O GloBallast foi criado pela parceria entre o Programa das Nações Unidas para o Desenvolvimento, o Fundo Global para o Meio Ambiente e a IMO, com o intuito de promover a cooperação internacional para mitigar os impactos da água de lastro, auxiliando os países em desenvolvimento a reduzir os riscos inerentes desta operação.

Tal sistema foi aprimorado com a parceria público-privada, por meio da Aliança da Indústria Global (GIA), do Fundo GIA, estabelecido com parceiros de grandes empresas marítimas e do Banco Europeu de Reconstrução e Desenvolvimento, que derivou o chamado IMO-EBRD Marine Biosafety Initiative (MBI).

Como as principais diretrizes de governança da água de lastro, destacamos: a expansão das capacidades governamentais e de gestão portuária; o incentivo de reformas legais, políticas e institucionais, em âmbito nacional; o desenvolvimento de mecanismos de sustentabilidade; estímulo à coordenação e cooperação regional; avaliação de risco; avaliação de risco da água de lastro; levantamento da biota do porto; medidas de gestão de água de lastro; recursos e autofinanciamento (SERAFIN; HENKES, 2013).

De toda sorte, deve-se ressaltar que ainda não existe, no Brasil, nenhum plano nacional de gerenciamento de água de lastro, ou estratégias de implementação das diretrizes da governança da água de lastro, embora tenha sido aprovado o Plano de Trabalho Nacional de Avaliação de Risco da Água de Lastro. 


\section{A ELEVAÇÃO DOS RISCOS DE BIOINVASÃO EM FACE DAS PROJEÇÕES DE CRESCIMENTO DO PORTO DE VILA DO CONDE}

\subsection{Bioinvasão por água de lastro no Brasil}

Um volume entre 3 e 5 bilhões de toneladas de água de lastro são transportadas todos os anos, no mundo (BRASIL, 2012).

As principais consequências negativas da introdução de espécies exóticas e nocivas incluem: o desequilíbrio ecológico das áreas invadidas, com a possível perda de biodiversidade; prejuízos em atividades econômicas utilizadoras de recursos naturais afetados, gerando a consequente desestabilização social de comunidades que dependem diretamente das águas como fonte de trabalho e subsistência; há ainda a disseminação de enfermidades em populações costeiras, causadas pela introdução de organismos patogênicos.

O primeiro caso de bioinvasão causada por água de lastro que ganhou repercussão internacional, com impacto direto no Brasil, foi o do mexilhão-dourado (Limnoperna fortunei). Originário de águas asiáticas, a espécie invasora foi avistada pela primeira vez no continente americano em 1991, no Rio da Prata, na Argentina (COLLYER, 2007).

Dentre os prejuízos causados pelo mexilhão, podemos destacar: destruição da vegetação aquática; ocupação do espaço e disputa por alimento com os moluscos nativos; prejuízos à pesca; entupimento de canos, dutos, filtros de água, dentre outros equipamentos instalados em ambiente aquaviário, entupimento de sistemas hidroelétricos, comprometimento da segurança da navegação, interferindo na estrutura dos equipamentos de sinalização e cascos das embarcações.

No Brasil, o molusco invasor foi avistado pela primeira vez em 1999, no Rio Grande do Sul, sendo encontrado, hoje, em Estados da Região Sul, Sudeste e Centro-Oeste.

Nacionalmente, o caso que ganhou repercussão foi o do siri Charybdis hellerii, trazido por água de lastro, provavelmente, coletada no Caribe, avistado pela primeira vez no ano de 1996. O agente invasor é encontrado no Rio de Janeiro, São Paulo, Alagoas e Bahia. O artrópode, que não possui valor comercial, vem substituindo as espécies de siris nativas, prejudicando os pescadores locais, além de hospedar o vírus da mancha branca (White spot syndrome vírus - WSSV), causador da síndrome da mancha branca, 
que afeta outras espécies marinhas, resultando, muitas vezes, na morte dos animais contaminados. (SÃO PAULO, 2010)

A ANVISA, em 2002, apontou a presença de bactérias marinhas em $71 \%$ das amostras, objeto de análise, de água de lastro. Deste total, foram identificados:

[...] o transporte de vibrios (31\%), coliformes fecais (13\%), Escherichia coli (5\%), Enterococos fecais (22\%), Closdridium perfringens (15\%), colifagos (29\%), Vibrio cholerae O1(7\%), e de Cholerae não O1(23\%) em amostras de água de lastro e (21\%) em amostras plâncton, 12 cepas em sete amostras foram identificadas como V. C. O1EL TOR, sendo duas toxigênicas (SERAFIN; HENKES, 2013, p. 94-95).

No Pará,já foi encontrada a espécie exótica asiática corbicula flumínea no município de Alenquer e nas proximidades de Santarém, na Bacia Amazônica. Até o presente momento, não foram realizadas pesquisas que pudessem aferir a existência de impactos sobre a saúde humana e influências negativas para comunidades tradicionais que habitam ilhas próximas ao local afetado, mas essa região é de grande sensibilidade ambiental, tendo o rio, influência direta na vida de pescadores, quilombolas, povos indígenas e comunidades locais dos Municípios próximos. Com efeito, é necessário um cuidado redobrado com a operação de lastro nas bacias fluviais (HAGER, 2008).

\subsection{Projeções de crescimento do Porto de Vila do Conde e elevação dos riscos de poluição}

O porto organizado de Vila do Conde está localizado no interior do Pará, na cidade de Barcarena, na margem direita do Rio Pará, no local denominado Ponta Grossa, confluência dos rios Amazonas, Tocantins, Guamá e Capim. Possui acesso rodoviário através da BR-316, seguindo pela Alça Viária até o encontro com a PA-151 e, posteriormente, PA-483 e PA-481, totalizando $120 \mathrm{~km}$ da capital Belém.

Sua localização foi decidida considerando-se a proximidade da Usina Hidrelétrica de Tucuruí, de Belém (metrópole de apoio), a posição geográfica central do munícipio em relação às jazidas de bauxita de Trombetas e Paragominas, a disponibilidade de acesso marítimo (através do Canal do Quiriri), além de amplas áreas para instalação portuária e industrial. É válido ressaltar a área de influência geoeconômica do porto no sentido do mar, com a proximidade do continente Europeu e Asiático (através do Canal do Panamá), comparado a outros portos brasileiros. 
O porto organizado de Vila do Conde possui a maior movimentação da Região Norte.

Em 2013, foi divulgado o Plano Mestre do Porto de Vila do Conde, destacando as principais características do porto, projeções de crescimento e expansão até o ano de 2030. Estimou-se que a quantidade de carga transportada entre os anos de 2011 e 2030 iria mais do que triplicar, passando de aproximadamente $16.000(\mathrm{t})$, para $53.000(\mathrm{t})$. (BRASIL, 2013).

O Brasil sofreu, ao longo dos últimos anos, uma grave crise econômica, derivada de diversos fatores, com destaque para a crise política e os diversos escândalos de corrupção, que tiveram uma influência negativa sobre a economia no ano de 2016. Entretanto, em 2017 e 2018 o Porto de Vila do Conde cresceu acima projeções. Os dados do anuário da Agência Nacional dos Transportes Aquaviários do ano de 2016, apontam que o Porto de Vila do Conde movimentou cerca de 14.796.941 (t), bem abaixo da previsão do plano mestre, que previa movimentação de $25.000(\mathrm{t})$. Em 2017 e 2018, porém, as movimentações de cargas superam as projeções, alcançando $35.436 .372(\mathrm{t})$ e $33.071 .712(\mathrm{t})$, enquanto estas previam algo em torno de $26.000(\mathrm{t})$ e $28.000(\mathrm{t})$, respectivamente. (ANTAQ, 2018)

O aumento da movimentação de carga do Porto de Vila do Conde, está diretamente relacionado com o aumento do tráfego de navios mercantes e, por conseguinte, um aumento expressivo do volume de água de lastro despejado na região, que representa um agravamento do risco de bioinvasão por introdução. Todavia, não há uma perspectiva concreta de aumento na eficiência do controle da água de lastro, ou de exigência, para os navios, de incorporação de equipamentos que possibilitem o tratamento, a bordo, desta água.

Neste contexto, o agravamento do risco de poluição está diretamente relacionado, de forma cumulativa, ao aumento movimentação de navios. Os problemas da legislação afetam a matéria e a precariedade da fiscalização.

No caso da Região Amazônica, as dificuldades de fiscalização são agravadas pela extensão das áreas navegáveis e o grande número de embarcações que trafega na área, sejam de navegação interior, seja de navegação em mar aberto.

Outro ponto que merece destaque é a grande diversidade de comunidades tradicionais que habitam a região. A identidade de várias comunidades tradicionais amazônicas implica em uma pluralidade de relações e valorações da fauna aquática (ROMAGNOLI, 2016). 
O rio, para essas comunidades, constitui um espaço de reprodução do seu cotidiano, estando intimamente ligado à cultura, subsistência, lazer, transporte, atividades domésticas, comércio, dentre outros. É dele que se retira o peixe para a venda e para alimentação (FERREIRA, 2013) e é por ele que se dá a locomoção, o acesso às escolas, hospitais e localidades vizinhas para permuta ou venda dos insumos extraídos da natureza: "A dinâmica imposta pelo ciclo das águas, que num momento mata e no outro ressuscita, faz crer, para esses homens mulheres e crianças, que o que prevalece, no final das contas, é a vida - por isso lá permanecem" (WITKOSKI, 2007, p. 20). Diante dessa alta capacidade de adaptação dinâmica dos rios, Harris (2006) destaca que a flexibilidade e a resiliência são características essenciais destas comunidades.

Paz (2007) estimou que, caso ocorra alteração ambiental nas áreas adjacentes ao Porto de Vila do Conte - o que inclui a Ilha do Capim -, as perdas econômicas para os ribeirinhos e pescadores artesanais do entorno, seria de, no mínimo $\mathrm{R} \$ 724.431,00$ (setecentos e vinte e quatro mil e quatrocentos e trinta e um reais), cumulado com perdas sociais.

Não há pesquisas acerca do impacto sanitário gerado por acidentes da navegação, ou industriais, que derivem em poluição das águas na região, porém, há relatos de problemas dermatológicos e gastrointestinais dos moradores da referida ilha, durante períodos compatíveis com a ocorrência dos acidentes narrados.

A íntima relação com o rio, como parte de sua territorialidade, cultura e modo de vida, agrava a vulnerabilidades dessas comunidades tradicionais diante de um risco de poluição por água de lastro, que repercute em uma elevada possibilidade de afetação direta do território, do modo tradicional de vida, da economia, da saúde e da própria existência de algumas comunidades.

O transporte de bactérias pode derivar em diversas patologias de pessoas que estão em contato direto com esta água. O desequilíbrio causado por uma espécie invasora, como observado no caso do siri Charybdis hellerii, pode repercutir em diminuição e/ou extinção de espécies nativas, relacionadas ao comércio e a alimentação destas comunidades.

\section{CONCLUSÃO}

A água de lastro representa um risco real a todos os que habitam a Região Amazônica. Os precedentes de poluição no território brasileiro 
já causaram diversos prejuízos à saúde humana (cólera), à economia de populações locais (siri Charybdis hellerii) e à indústria (mexilhão dourado).

A fiscalização do tratamento da água de lastro é materialmente falha, por exigir apenas informações por meios documentais, existindo relatos de alterações de dados até mesmo pela tripulação dos navios. Em que pese a possibilidade, pouco utilizada, de realização de exames para apurar a veracidade das informações, e formalmente falha, por flexibilizar em excesso as exigências de tratamento, priorizando sempre o interesse comercial em detrimento da prevenção dos impactos ambientais.

A NORMAM 20 considera as águas interiores, de forma bastante equivocada, como um único ecossistema, dispensando a troca da água de lastro por navios que realizem esse tipo de navegação, agravando os riscos de poluição ambiental.

O Porto de Vila do Conde vem apresentando uma constância no crescimento anual, aproximando-se, cada vez mais, das projeções do Plano Mestre, que prevê um aumento da movimentação de carga três vezes maior que a movimentação observada no ano de 2011, o que indica um maior número de navios na região e, por conseguinte, o aumento do volume de água deslastrada na área portuária e nos seus entornos.

O risco de poluição por água de lastro na Região Amazônica é agravado pela ineficiência da regulação, ineficácia da fiscalização e aumento do volume deslastrado.

Em que pese a impossibilidade de estabelecer, previamente, as repercussões de um eventual dano concreto, a vulnerabilidade das comunidades tradicionais amazônicas, sobretudo aquelas que habitam o entorno do Porto de Vila do Conde, é potencializada em função da sua interação direta com o rio, ofendendo, desta forma, a territorialidade dessas comunidades.

Uma reformulação da NORMAM 20, que promova uma regulação eficiente, priorizando a prevenção dos impactos ambientais causados por água de lastro, com exigências de exames de constatação da veracidade das informações prestadas nos formulários e nos livros de água de lastro, acompanhada de políticas de implementação de condições necessárias para que a autoridade marítima promova a correta fiscalização (recursos humanos, treinamento e aparelhamento), são condições essenciais para mitigar e, como prevê a BWM, eliminar os riscos de poluição causada por água de lastro, respeitando a territorialidade e a dignidade das comunidades 
tradicionais amazônicas.

O estabelecimento de padrões gerais, em âmbito nacional, para a gestão ambiental da água de lastro, observando (e cumprindo) as diretrizes de uma boa governança, faz-se necessário.

Como medidas essenciais, destacamos: a necessidade de levantamentos da biodiversidade em regiões sensíveis; o mapeamento das regiões socioambientalmente sensíveis; aparelhamento adequado dos agentes fiscalizadores; atuação integrada da autoridade marítima, autoridade portuária, administração do porto, do município, do Estado, e das comunidades locais; campanhas de conscientização de tripulantes de navios e das comunidades locais, sobre os riscos da água de lastro; procedimento de fiscalização eficaz, que reduza e/ou elimine a possibilidade de fraudes das informações prestadas.

Essas medidas técnicas certamente ajudariam sobremaneira na coexistência da navegação do Porto de Vila do Conde com as comunidades identitariamente instaladas e dependentes do Rio.

\section{REFERÊNCIAS}

ANTAQ - AGÊNCIA NACIONAL DOS TRANSPORTES AQUAVIÁRIOS. Estatístico aquaviário. Brasília, DF: Agência Nacional de Transportes Aquaviários, 2019. Disponível em: < http://web.antaq.gov. br/Anuario/>. Acesso em: 18 jun. 2019.

BOLDRINI, E. B.; PROCOPIAK, L. K. Projeto água de lastro: diagnóstico, dificuldades e medidas preventivas contra a bioinvasão de espécies exóticas por água de lastro de navios nos terminais portuários de Ponta do Félix S.A. Porto de Antônia-PR. Brasília DF: Ministério do Meio Ambiente, 2005. Disponível em: <http://www.mma.gov.br/ estruturas/174/_arquivos/174_05122008105057.pdf >. Acesso em: 10 jun. 2017.

BRASIL. [Constituição (1988)]. Constituição da República Federativa do Brasil de 1988. Brasília, DF: Presidência da República, 1988. Disponível em: <http://www.planalto.gov.br/ccivil_03/Constituicao/Constituicao. htm>. Acesso em: 19 jan. 2019.

BRASIL. Lein. 9.537, de 11 de dezembro de 1997. Dispõe sobre a segurança do tráfego aquaviário em águas sob jurisdição nacional e dá outras providências. Brasília, DF: Presidência da República, 1997. Disponível 
em: <http://www.planalto.gov.br/ccivil_03/LEIS/L9537.HTM>. Acesso em: 22 jan. 2019.

BRASIL. Lei n. 9.605, de 12 de fevereiro de 1998. Dispõe sobre as sanções penais e administrativas derivadas de condutas e atividades lesivas ao meio ambiente, e dá outras providências. Brasília, DF: Presidência da República, 1998. Disponível em: <http://www.planalto.gov.br/ccivil_03/leis/19605. htm>. Acesso em: 15 jun. 2017.

BRASIL. Agência Nacional de Vigilância Sanitária. Brasil - Água de lastro - ANVISA: Projetos GGPAF 2002. Brasília, DF: Anvisa, 2002a.

BRASIL. Ministério do Meio Ambiente. Biodiversidade Brasileira avaliação e identificação de áreas e ações prioritárias para a conservação, utilização sustentável e repartição dos beneficios da biodiversidade dos biomas brasileiros, 2002. Brasília, DF: Ministério do Meio Ambiente, 2002b. Disponível em: <http://www.mma.gov.br/estruturas/chm/_ arquivos/Bio5.pdf $>$. Acesso em: 14 jun. 2017.

BRASIL. Decreto n. 6.514, de 22 de julho de 2008. Dispõe sobre as infrações e sanções administrativas ao meio ambiente, estabelece o processo administrativo federal para apuração destas infrações, e dá outras providências. Brasília, DF: Presidência da República, 2008. Disponível em: <http://www.planalto.gov.br/ccivil_03/_ato2007-2010/2008/decreto/ d6514.htm>. Acesso em: 5 mar. 2018.

BRASIL. Agência Nacional de Vigilância Sanitária. Resolução de Diretoria Colegiada-RDCn.72, de29dedezembrode2009.DispõesobreoRegulamento Técnico que visa à promoção da saúde nos portos de controle sanitário instalados em território nacional, e embarcações que por eles transitem. Brasília, DF: Minstério da Saúde, 2009. Disponível em: <http://portal. anvisa.gov.br/documents/10181/2718376/\%281\%29RDC_72_2009 COMP.pdf/3dff4bbd-779f-43ba-821c-f48f380376fd $>$. Acesso em: 5 mar. 2017.

BRASIL. Ministério do Meio Ambiente. Água de lastro - Tecnologias de tratamento. Brasília, DF: Ministério do Meio Ambiente, 2012. Disponível em: <http://www.mma.gov.br/clima/convencao-das-nacoes-unidas/protocolo-de-quioto/itemlist/category/111-agua-de-lastro.html>. Acesso em: 30 jun. 2017. 
BRASIL. Marinha do Brasil. Diretoria dos Portos e Costas. Norma da Autoridade Maritima para Trafego e Permanência de Embarcações em Águas Jurisdicionais Brasileiras - NORMAM 08/DPC. Rio de Janeiro: Marinha do Brasil, 2013. Disponível em: <https:/www.marinha.mil.br/ dpc/sites/www.marinha.mil.br.dpc/files/NORMAM08_1.pdf $>$. Acesso em: 2 mar. 2017.

BRASIL. Marinha do Brasil. Diretoria dos Portos e Costas. Norma da Autoridade Maritima para o Gerenciamento da Água de Lastro de Navios - NORMAM-20/DPC. Rio de Janeiro: Marinha do Brasil, 2014. Disponível em: $<$ https://www.marinha.mil.br/dpc/sites/www.marinha.mil.br.dpc/files/ normam20_2.pdf $>$. Acesso em: 2 mar. 2017.

BRASIL. Câmara dos Deputados. Centro de Estudos e Debates Estratégicos. Consultoria Legislativa. Arco norte: o desafio logístico. Brasília, DF: Câmara dos Deputados, 2016.

COLLYER, W. Água de lastro, bioinvasão e resposta internacional. Revista Jurídica da Presidência da República, Brasília, v. 9, n. 84, p. 145-160, abr./ maio 2007. Disponível em: <http://www.planalto.gov.br/ccivil_03/revista/ Rev_84/artigos/WesleyCollyer_rev84.htm>. Acesso em: 30 mar. 2017.

FERREIRA, L. D. S. G. Gênero de vida ribeirinho na Amazônia: reprodução socioespacila na região das ilhas de Abaetetuba - PA. Dissertação (Mestrado em Geografia) - Instituto de Filosofia e Ciências Humanas, Universidade Federal do Pará, Belém, 2013.

HAGER, A. X. Identificação genética de espécies exóticas invasoras do filo mollusca nos Rios Tapajós e Amazonas, mesorregião do Baixo Amazonas, Estado do Pará. Dissertação (Mestrado em Genética e Biologia Molecular) - Instituto de Ciências Biológicas, Universidade Federal do Pará, Belém, 2008.

HARRIS, M. Presente ambivalente: uma maneira amazônica de estar no tempo. In: ADAMS, C.; MURRIETA, R.; NEVES, W. Sociedades caboclas amazônicas: modernidade e invisibilidade. São Paulo: Annablume, 2006. p. 81-108.

JUNK, W. J. Recursos hídricos da região amazônica: utilização e prevenção. Acta Amaz, Manaus, v. 9, n. 4, p. 37-51, dez. 1979. Disponível em: $<$ http://www.scielo.br/scielo.php?script=sci_arttext\&pid=S004459671979000800037\&lng=pt\&nrm=iso $>>$. Acesso em: 14 jun. 2017. 
LUZ DE SOUZA, R. C. C. Água de lastro: uma ameaça à biodiversidade. In: REUNIÃO ANUAL DA SBPC, 62., Natal. Anais [...]. Natal: Universidade Federal Fluminense, 2010. p. 1-3.

MARTINS, E. M. O. Curso de Direito Marítimo, volume I: teoria geral. 4. ed. Barueri: Manole, 2013.

ONU - ORGANIZAÇÃO DAS NAÇÕES UNIDAS. Convenção sobre Diversidade Biológica. Rio de Janeiro (Município): ONU, 1992. Disponível em: <http://www.mma.gov.br/estruturas/sbf_dpg/_arquivos/cdbport.pdf>. Acesso em: 25 jan. 2018.

ORGANIZAÇÃO MARÍTIMA INTERNACIONAL. Convenção Internacional para o Controle e Gerenciamento da Água de Lastro e Sedimentos de Navios. Londres: IMO, 2004. Disponível em: <https:// www.ccaimo.mar.mil.br/sites/default/files/convencao_bwm.pdf $>$. Acesso em: 30 mar. 2017.

PAZ, A. C. Pesca Ictiofauna na área adjacente ao terminal de Vila do Conde - Pará, Brasil. Dissertação (Mestrado em Ciência Animal) Núcleo de Estudos em Ciência Animal, Universidade Federal do Pará, Belém, 2007.

PROCOPIAK, L. K. O conhecimento dos comandantes de navios sobre a bioinvasão por água de lastro nos portos do Estado do Paraná e a Importância da educação ambiental. Tese (Doutorado em Meio Ambiente e Desenvolvimento) - Setor de Ciências Agrárias, Universidade Federal do Paraná, Curitiba, 2009.

ROMAGNOLI, F. C. A vida flutuante na várzea: readaptação como elemento fundamental para a conservação de recursos aquáticos. Tese (Doutorado em Desenvolvimento Sustentável do Trópico Úmido) - Núcleo de Altos Estudos Amazônicos, Universidade Federal do Pará, Belém, 2016.

SÃO PAULO (Estado). Secretaria de Agricultura do Governo de São Paulo. Instituto Biológico. Mancha branca do camarão: um risco presente para a produção de camarão marinho no Brasil. São Paulo, 2010.

SECRETARIA DE PORTOS DA PRESIDÊNCIA DA REPÚBLICA (Brasil); UNIVERSIDADE FEDERAL DE SANTA CATARINA; LABORATÓRIO DE TRANSPORTE E LOGÍSTICA. Plano Mestre: Porto de Vila do Conde. Brasília, DF: SEP; Florianópolis, SC: UFSC; 
Florianópolias, SC: LabTrans, 2013. Disponível em: $<$ http://infraestrutura. gov.br/images/planos-mestres-sumarios-executivos/se33.pdf $>$. Acesso em: 18 jun. 2018.

SERAFIN, I. T.; HENKES, J. A. Água de lastro: um problema ambiental. Revista Gestão Sustentável Ambiental, Florianópolis, v. 2, n. 1, p. 92-112, abr./set. 2013. Disponível em: <http://www.portaldeperiodicos.unisul.br/ index.php/gestao_ambiental/article/download/1453/1110>. Acesso em: 17 jun. 2017.

SIQUEIRA, G. W. et al. Avaliação do risco ambiental da introdução de água de lastro no porto petroquímico de miramar (Belém do Pará): um estudo de caso. In: CONGRESSO BRASILEIRO DE OCEANOGRAFIA, 2012, Rio de Janeiro. Anais [...]. Balneário Camboriú: Associação Brasileira de Oceanografia, 2012.

USP - UNIVERSIDADE DE SÃO PAULO. Brasil pode ficar livre da bioinvasão por água de lastro. Centro de Inovação em Logística, 2013. Disponível em: $<\mathrm{http}: /$ www.usp.br/cilip/?p=935>. Acesso em: 10 jun. 2017.

WITKOSKI, A. C. Terras, florestas e águas de trabalho: os camponeses amazônicos e formas de usos de seus recursos naturais. 2. ed. São Paulo: Annablume, 2007.

Artigo recebido em: 27/02/2019. Artigo aceito em: 06/08/2019.

\section{Como citar este artigo (ABNT):}

SILVA, R. M.; MOREIRA, E. C. P. A água de lastro e a necessidade de efetividade das normas de proteção da biodiversidade marinha no contexto amazônico. Veredas do Direito, Belo Horizonte, v. 16, n. 35, p. 123-147, maio/ago. 2019. Disponível em: <http://www.domhelder.edu.br/revista/ index.php/veredas/article/view/1496>. Acesso em: dia mês. ano. 